\title{
Synthesis and biological evaluation of shikimic acid derivatives
}

\author{
Van Hung Nguyen a, Van Cuong Pham ${ }^{\text {a,* }}$, Huong Doan Thi Mai a, Thanh Nguyen Le a, \\ Thi Minh Hang Nguyen a, Van Nam Vu a, Huu Giap Tran a, Thi Thao Do b, \\ Wim Dehaen c, and Van Minh Chau a
}

a Institute of Marine Biochemistry, Vietnam Academy of Science and Technology, 18 Hoang Quoc Viet Road, Cau Giay, Hanoi, Vietnam ${ }^{\mathrm{b}}$ Institute of Biotechnology, Vietnam Academy of Science and Technology, 18 Hoang Quoc Viet Road, Cau Giay, Hanoi, Vietnam

c Department of Chemistry, Cathonic University of Leuven, Celestijnenlaan 200F 3001, Leuven, Belgium

*Corresponding author at: Institute of Marine Biochemistry, Vietnam Academy of Science and Technology, 18 Hoang Quoc Viet Road, Cau Giay, Hanoi, Vietnam. Tel.: +84.4.37917049. Fax: +84.4.37917054.E-mail address: phamvc@imbc.vast.vn (V.C. Pham).

\section{ARTICLE INFORMATION}

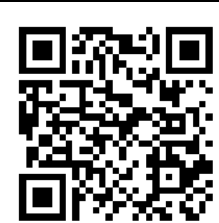

DOI: 10.5155 /eurjchem.5.4.601-606.1096

Received: 25 May 2014

Received in revised form: 14 July 2014

Accepted: 17 July 2014

Online: 31 December 2014

\section{KEYWORDS}

\section{Sulfur}

Azides

Amines

Cytotoxicity

Asymmetric synthesis

Nucleophilic substitution

\section{Introduction}

Shikimic acid is well known as starting material for production of oseltamivir phosphate (Tamiflu), an active neuraminidase inhibitor [1-5]. Although of some reports on total oseltamivir synthesis from other sources, shikimic acid remains the principal starting material for making oseltamivir. Shikimic acid is a key precursor for an enormous number of aromatic compounds, e.g. aromatic amino acids, vitamins and host of secondary metabolites [6-9], and is the ideal precursor for tracer studies because it is generally permeable to cells and is chemically stable. As shikimate pathway does not occur in mammals, much effort has been made to synthesize potential enzyme inhibitors in order to develop antimicrobial reagents. Many of these compounds, by virtue of their structural similarity to shikimic acid, have been targeted as likely inhibitor of enzyme on the shikimic acid pathway and are of biological interest as potential antifugal $[10,11]$, antibacterial [11], antitumor [12,13], and antiparasitic agents [14]. Besides its bio-significance, shikimic acid, which is a highly functionnalized carbocycle, is also an industrially useful chiral compound [15]. In our search of bioactive compounds based on shikimic acid, we reported here the synthesis and biological activity of oseltamivir analogues containing either ether sulfur or ether oxygen at C-3 position. To our knowledge, the synthesis of oseltamivir analogues with ether sulfur at C-3 has not been reported yet. Also, there are a few reports on the cytotoxicity of compounds based on shikimic acid, whereas several shikimic acid's derivatives have been found to be potential antitumor agents such as pericosines $[12,16]$. Furthermore, the plant star anise (Illicium verum), widely distributing in the tropical and subtropical zones of Asia is considered as a rich source for extracting shikimic acid which should be used as starting material for different purposes [17].

\section{Experimental}

\subsection{Instrumentation}

Chemical reagents were purchased from Aldrich Chemical Co. and used without further purification. Optical rotations were recorded on a Jasco P-2000 polarimeter in EtOH. Melting points were recorded on a MELTEMP3.0 instrument, and IR spectra were measured on a Nicolet Impact-410 FT-IR spectrometer. ESI-MS were recorded on an Agilent 1100 LC-MSD Trap spectrometer. 


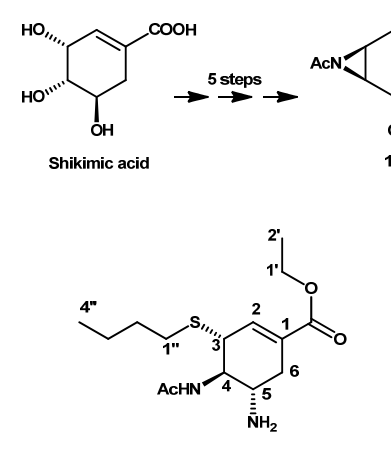

$4 a$
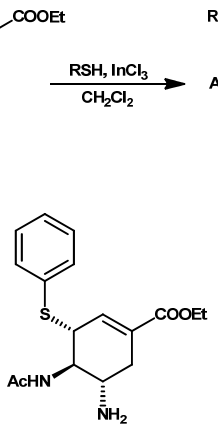

4b
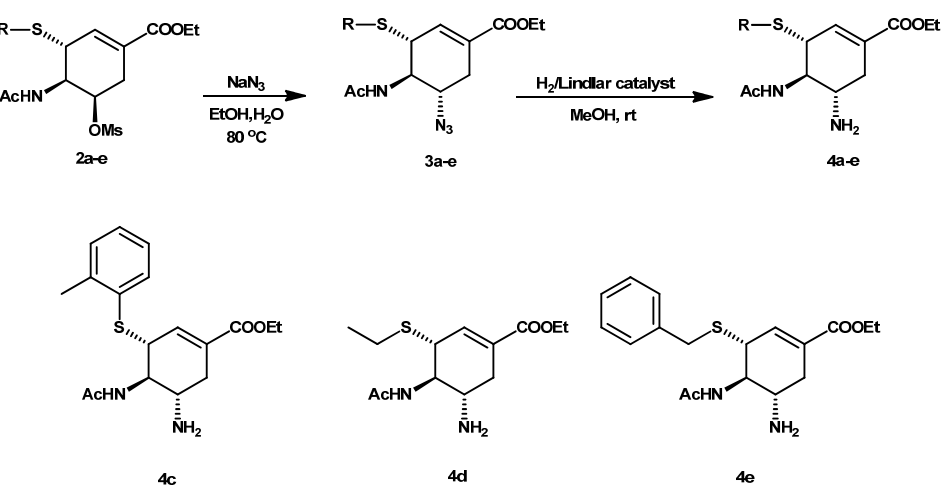

$4 c$

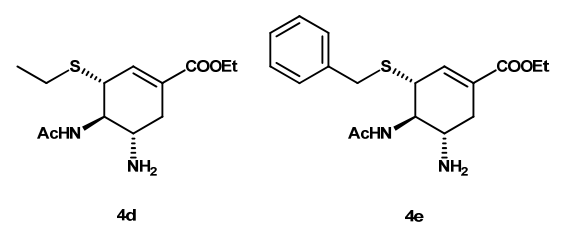

Scheme 1

The NMR spectra were recorded on a Bruker spectrometer operating at $500.13 \mathrm{MHz} .{ }^{1} \mathrm{H}$ chemical shifts were referenced to $\mathrm{CHCl}_{3}$ at 7.27, while the ${ }^{13} \mathrm{C}$ chemical shifts were referenced to the central peak of $\mathrm{CDCl}_{3}$ at 77.0. Column chromatography was performed on Merck silica gel 60 (70-230 mesh).

\subsection{Synthesis}

\subsubsection{General procedure for compounds $2 a-e$}

To a solution of $N$-acetyl aziridine $1(1.0 \mathrm{mmol})$ in dichloromethane $(5 \mathrm{~mL})$ was added $\mathrm{InCl}_{3}(20 \mathrm{mg}, 0.1 \mathrm{mmol})$ and thiols $(2.0 \mathrm{mmol})$. The reaction mixture was stirred at room temperature for $12 \mathrm{~h}$. The solids were filtered off and washed with dichloromethane. The filtrate was evaporated under vacuum to give crude products $\mathbf{2 a - e}$ which were used for the next step without purification (Scheme 1).

\subsubsection{General procedure for compounds $3 a-e$}

To a solution of compounds 2 a-e $(0.5 \mathrm{mmol})$ in a mixture of ethanol $(2 \mathrm{~mL})$ and water $(0.3 \mathrm{~mL})$ was added sodium azide $(10$ eq). The reaction mixture was heated at $80^{\circ} \mathrm{C}$ for $6 \mathrm{~h}$. Water $(20 \mathrm{~mL})$ was added and the mixture was extracted with EtOAc $(3 \times 20 \mathrm{~mL})$. The organic layers were combined, dried over sodium sulfate and concentrated under diminished pressure. The residue was purified over a silica gel column chromatography ( $n$-hexane/EtOAc gradient) yielding compounds 3a-e (Scheme 1).

Ethyl (3R,4R,5S)-4-acetamido-5-azido-3-(butylthio)cyclohex1-ene-1-carboxylate (3a): Color: Yellow, amorphous solid. Yield: 46.2\%. ${ }^{1} \mathrm{H}$ NMR $\left(500 \mathrm{MHz}, \mathrm{CDCl}_{3}, \delta, \mathrm{ppm}\right): 0.90(\mathrm{t}, J=7.2 \mathrm{~Hz}, 3 \mathrm{H}$, $\mathrm{CH}_{3}-4^{\prime \prime}$ ), 1.30 (t, $\left.J=7.2 \mathrm{~Hz}, 3 \mathrm{H}, \mathrm{CH}_{3}-2^{\prime}\right), 1.38\left(\mathrm{~m}, 2 \mathrm{H}, \mathrm{CH}_{2}-3^{\prime \prime}\right)$, $1.54\left(\mathrm{~m}, 2 \mathrm{H}, \mathrm{CH}_{2}-2^{\prime \prime}\right), 2.07$ (s, 3H, $\left.\mathrm{CH}_{3}-\mathrm{CO}\right), 2.25$ (m, $\left.1 \mathrm{H}, \mathrm{H}_{\mathrm{a}}-6\right)$, $2.52\left(\mathrm{~m}, 2 \mathrm{H}, \mathrm{CH}_{2}-1^{\prime \prime}\right), 2.90$ (dd, $\left.J=5.5,17.5 \mathrm{~Hz}, 1 \mathrm{H}, \mathrm{Hb}-6\right), 3.58$ (q, $J=9.0 \mathrm{~Hz}, 1 \mathrm{H}, \mathrm{H}-4), 3.76$ (br. d, $J=9.0 \mathrm{~Hz}, 1 \mathrm{H}, \mathrm{H}-3$ ), 4.04 (ddd, $J=5.5,9.0,10.0 \mathrm{~Hz}, 1 \mathrm{H}, \mathrm{H}-5), 4.22\left(\mathrm{q}, J=7.2 \mathrm{~Hz}, 2 \mathrm{H}, \mathrm{CH}_{2}-\right.$ $1^{\prime}$ ), $5.72(\mathrm{~d}, J=9.0 \mathrm{~Hz}, 1 \mathrm{H}, \mathrm{NH}), 6.88$ (br. s, $\left.1 \mathrm{H}, \mathrm{H}-2\right) .{ }^{13} \mathrm{C}$ NMR (125 MHz, $\left.\mathrm{CDCl}_{3}, \delta, \mathrm{ppm}\right): 13.5\left(1 \mathrm{C}, \mathrm{CH}_{3}\right), 14.1\left(1 \mathrm{C}, \mathrm{CH}_{3}\right), 21.9$ (1C, $\left.\mathrm{CH}_{3}\right), 23.4,29.7,29.8,31.6,45.6,55.4,58.9,61.0,127.9$, $139.1,165.5,171.1$.

Ethyl (3R,4R,5S)-4-acetamido-5-amino-3-(phenylthio)cyclo hex-1-ene-1-carboxylate (3b): Color: Yellow, amorphous solid. Yield: $42 \% .{ }^{1} \mathrm{H}$ NMR $\left(500 \mathrm{MHz}, \mathrm{CDCl}_{3}, \delta, \mathrm{ppm}\right): 1.27(\mathrm{t}, J=7.3$ $\left.\mathrm{Hz}, 3 \mathrm{H}, \mathrm{CH}_{3}-2^{\prime}\right), 1.98$ (s, 3H, Ac), $2.01\left(\mathrm{~m}, 1 \mathrm{H}, \mathrm{H}_{\mathrm{a}}-6\right), 2.80$ (dd, $J=$ 5.0, $17.5 \mathrm{~Hz}, 1 \mathrm{H}, \mathrm{Hb}-6), 3.68(\mathrm{q}, J=8.7 \mathrm{~Hz}, 1 \mathrm{H}, \mathrm{H}-4), 3.93(\mathrm{~m}, 1 \mathrm{H}$, H-5), 4.12 (br. d, $J=8.7 \mathrm{~Hz}, 1 \mathrm{H}, \mathrm{H}-3), 4.21\left(\mathrm{~m}, 2 \mathrm{H}, \mathrm{CH}_{2}-1^{\prime}\right.$ ), 6.43 (d, $J=8.7 \mathrm{~Hz}, 1 \mathrm{H}, \mathrm{NH}), 6.90$ (br. s, $1 \mathrm{H}, \mathrm{H}-2), 7.26-7.32(\mathrm{~m}, 3 \mathrm{H}$, Ar-H-2", H-6" and H-4" $), 7.46$ (m, 2H, Ar-H-3" and $\left.\mathrm{H}-5^{\prime \prime}\right) .{ }^{13} \mathrm{C}$ $\operatorname{NMR}\left(125 \mathrm{MHz}, \mathrm{CDCl}_{3}, \delta, \mathrm{ppm}\right): 14.1,23.3,29.7,49.2,55.6,58.9$, $61.0,128.2,128.4,129.1,131.8,134.0,138.1,165.4,171.1$.
Ethyl (3R,4R,5S)-4-acetamido-5-amino-3-(o-tolylthio)cyclo hex-1-ene-1-carboxylate (3c): Color: Yellow, amorphous solid. Yield: $40 \% .{ }^{1} \mathrm{H}$ NMR $\left(500 \mathrm{MHz}, \mathrm{CDCl}_{3}, \delta, \mathrm{ppm}\right): 1.27(\mathrm{t}, J=7.2$ $\left.\mathrm{Hz}, 3 \mathrm{H}, \mathrm{CH}_{3}-2^{\prime}\right), 1.93$ (s, 3H, Ac), $2.16\left(\mathrm{~m}, 1 \mathrm{H}, \mathrm{H}_{\mathrm{a}}-6\right), 2.44(\mathrm{~s}, 3 \mathrm{H}$, $\mathrm{CH}_{3}-7^{\prime \prime}$ ), 2.85 (dd, $\left.J=4.5,17.5 \mathrm{~Hz}, 1 \mathrm{H}, \mathrm{H}_{\mathrm{b}}-6\right), 3.67(\mathrm{q}, J=9.0 \mathrm{~Hz}$, $1 \mathrm{H}, \mathrm{H}-4$ ), 4.04 (ddd, $J=5.0,9.0,9.0 \mathrm{~Hz}, 1 \mathrm{H}, \mathrm{H}-5), 4.18(\mathrm{~m}, 2 \mathrm{H}$, $\mathrm{CH}_{2}-1^{\prime}$ ), 4.19 (m, 1H, H-3), 6.16 (br. s, $\left.1 \mathrm{H}, \mathrm{NH}\right), 6.84$ (br. s, $1 \mathrm{H}$, $\mathrm{H}-2$ ) , 7.12-7.25 (m, 3H, Ar-H-4" ${ }^{\prime \prime} \mathrm{H}-5^{\prime \prime}$ and H-6" $\left.{ }^{\prime \prime}\right), 7.45$ (d, J = 7.5 $\left.\mathrm{Hz}, 1 \mathrm{H}, \mathrm{Ar}-\mathrm{H}-3^{\prime \prime}\right) .{ }^{13} \mathrm{C}$ NMR $\left(125 \mathrm{MHz}, \mathrm{CDCl}_{3}, \delta, \mathrm{ppm}\right): 14.1,20.9$, $23.3,29.8,48.4,56.5,58.7,61.0,126.6,127.7,128.3,130.7$, $132.3,133.6,137.5,140.7,165.5,171.1$.

Ethyl (3R,4R,5S)-4-acetamido-5-amino-3-(ethylthio)cyclo hex-1-ene-1-carboxylate (3d): Color: White, amorphous solid. Yield: 38\%. ${ }^{1} \mathrm{H}$ NMR (500 MHz, $\left.\mathrm{CDCl}_{3}, \delta, \mathrm{ppm}\right): 1.22(\mathrm{t}, J=7.2$ $\left.\mathrm{Hz}, 3 \mathrm{H}, \mathrm{CH}_{3}-2^{\prime \prime}\right), 1.29\left(\mathrm{t}, J=7.2 \mathrm{~Hz}, 3 \mathrm{H}, \mathrm{H}-2^{\prime}\right), 2.06$ (s, 3H, Ac), 2.23 (m, 1H, Ha-6), 2.53 (m, 2H, $\left.\mathrm{CH}_{2}-1^{\prime \prime}\right), 2.87$ (dd, $J=5.0,17.5$ $\mathrm{Hz}, 1 \mathrm{H}, \mathrm{Hb}-6), 3.67$ (m, 1H, H-4), 3.69 (m, 1H, H-3), 3.95 (ddd, J= 5.0, 9.5, 9.5 Hz, 1H, H-5), 4.20 (q, $J=7.2 \mathrm{~Hz}, 2 \mathrm{H}, \mathrm{CH}_{2}-1^{\prime}$ ), 6.16 (br. s, $1 \mathrm{H}, \mathrm{NH}), 6.88$ (br. s, $1 \mathrm{H}, \mathrm{H}-2) \cdot{ }^{13} \mathrm{C}$ NMR $\left(125 \mathrm{MHz}, \mathrm{CDCl}_{3}\right.$, $\delta$, ppm): 14.1, 14.6, 23.4, 24.1, 29.8, 45.5, 55.2, 58.9, 61.0, 127.9, $139.1,165.5,171.1$.

Ethyl (3R,4R,5S)-4-acetamido-5-amino-3-(benzylthio)cyclo hex-1-ene-1-carboxylate (3e): Color: Yellow, amorphous solid. Yield: 39\%. ${ }^{1} \mathrm{H}$ NMR $\left(500 \mathrm{MHz}, \mathrm{CDCl}_{3}, \delta, \mathrm{ppm}\right): 1.29(\mathrm{t}, J=7.2$ $\left.\mathrm{Hz}, 3 \mathrm{H}, \mathrm{CH}_{3}-2^{\prime}\right), 2.00$ (s, 3H, Ac), $2.20\left(\mathrm{~m}, 1 \mathrm{H}, \mathrm{H}_{\mathrm{a}}-6\right), 2.83$ (dd, $J=$ 5.0, $\left.17.5 \mathrm{~Hz}, 1 \mathrm{H}, \mathrm{H}_{\mathrm{b}}-6\right), 3.62(\mathrm{~m}, 1 \mathrm{H}, \mathrm{H}-3), 3.68(\mathrm{~m}, 1 \mathrm{H}, \mathrm{H}-4)$, $3.74\left(\mathrm{~d}, J=13.0 \mathrm{~Hz}, 1 \mathrm{H}, \mathrm{H}_{\mathrm{a}}-1^{\prime \prime}\right), 3.80\left(\mathrm{~d}, J=13.0 \mathrm{~Hz}, 1 \mathrm{H}, \mathrm{H}_{\mathrm{b}}-1^{\prime \prime}\right)$, 3.91 (ddd, $J=4.5,10.0,10.0 \mathrm{~Hz}, 1 \mathrm{H}, \mathrm{H}-5), 4.17(\mathrm{q}, J=7.2 \mathrm{~Hz}, 2 \mathrm{H}$ $\mathrm{CH}_{2}-1^{\prime}$ ), 5.56 (d, $\left.J=7.0 \mathrm{~Hz}, 1 \mathrm{H}, \mathrm{NH}\right), 6.78$ (br. s, $1 \mathrm{H}, \mathrm{H}-2$ ), $7.22-$ $7.31(\mathrm{~m}, 5 \mathrm{H}, \mathrm{Ar}-\mathrm{H}) .{ }^{13} \mathrm{C}$ NMR (125 MHz, $\left.\mathrm{CDCl}_{3}, \delta, \mathrm{ppm}\right): 14.1$, $23.5,29.7,34.9,45.4,54.9,58.7,61.0,127.4,127.8,128.6$, $129.0,137.6,138.6,165.4,170.8$.

\subsubsection{General procedure for the synthesis of compound 4a-e}

To a mixture of compounds 3a-e $(0.1 \mathrm{mmol})$ in methanol (2 $\mathrm{mL}$ ) was added Lindlar's catalyst $(10 \mathrm{mg})$. The reaction mixture was stirred under hydrogen atmosphere for $5 \mathrm{~h}$. The solids were filtered off and washed with methanol. The filtrate was concentrated to dryness. The residue was purified by silica gel column chromatography eluted with $\mathrm{CH}_{2} \mathrm{Cl}_{2}: \mathrm{MeOH}(20: 1, v: v)$ to provide compounds $\mathbf{4 a - e}$ (Scheme 1 ).

$(3 R, 4 R, 5 S)$-ethyl 4-acetamido-5-amino-3-(butylthio)cyclo hex-1-enecarboxylate (4a): Color: White, amorphous solid. Yield: $82 \%$. $[\alpha]_{\mathrm{D}}{ }^{25}:-30.8\left(c, 0.15, \mathrm{CHCl}_{3}\right) .{ }^{1} \mathrm{H}$ NMR $(500 \mathrm{MHz}$, $\left.\mathrm{CDCl}_{3}, \delta, \mathrm{ppm}\right): 0.88\left(\mathrm{t}, J=7.5 \mathrm{~Hz}, 3 \mathrm{H}, \mathrm{CH}_{3}-4^{\prime \prime}\right), 1.28(\mathrm{t}, J=7.0 \mathrm{~Hz}$, $\left.3 \mathrm{H}, \mathrm{CH}_{3}-2^{\prime}\right), 1.38\left(\mathrm{~m}, 2 \mathrm{H}, \mathrm{CH}_{2}-3^{\prime \prime}\right), 1.52\left(\mathrm{~m}, 2 \mathrm{H}, \mathrm{CH}_{2}-2^{\prime \prime}\right), 2.08(\mathrm{~s}$, $3 \mathrm{H}, \mathrm{Ac}), 2.24\left(\mathrm{~m}, 1 \mathrm{H}, \mathrm{H}_{\mathrm{a}}-6\right), 2.46\left(\mathrm{~m}, 1 \mathrm{H}, \mathrm{H}_{\mathrm{a}}-\mathrm{1}^{\prime \prime}\right), 2.54\left(\mathrm{~m}, 1 \mathrm{H}, \mathrm{H}_{\mathrm{b}}-\right.$ $\left.1^{\prime \prime}\right), 2.88\left(\mathrm{~m}, 1 \mathrm{H}, \mathrm{H}_{\mathrm{b}}-6\right), 3.20(\mathrm{~m}, 1 \mathrm{H}, \mathrm{H}-5), 3.47$ (br. d, $J=9.7 \mathrm{~Hz}$, $1 \mathrm{H}, \mathrm{H}-3), 3.81(\mathrm{q}, J=9.7 \mathrm{~Hz}, 1 \mathrm{H}, \mathrm{H}-4), 4.17(\mathrm{q}, J=7.0 \mathrm{~Hz}, 2 \mathrm{H}$, $\mathrm{CH}_{2}-1^{\prime}$ ), 6.53 (br. s, 1H, NH), 6.86 (br. s, 1H, H-2). 


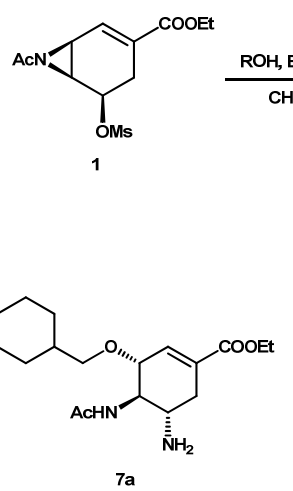

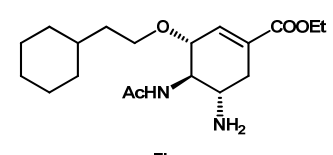

$7 \mathbf{b}$

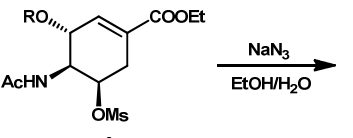

$5 a-f$<smiles>[2H][C@@H]1C=C(C(=O)OCC)C[C@@H](N)[C@H]1N=[W]</smiles>
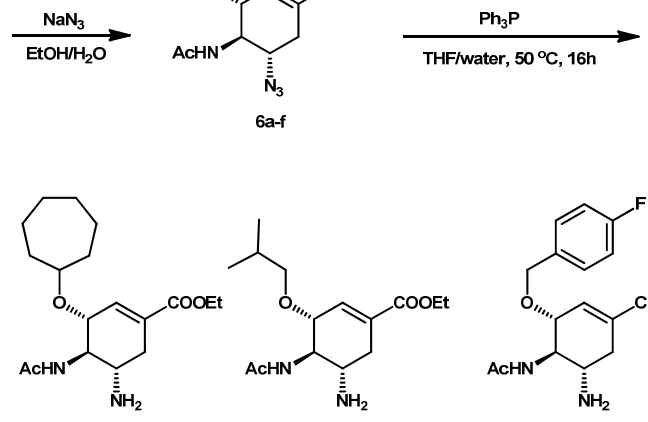

7c

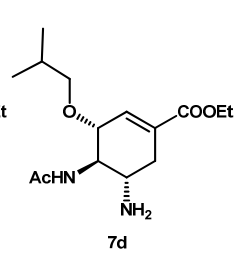

$7 \mathrm{~d}$

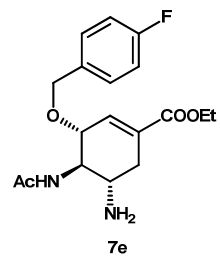

$7 e$<smiles>[2H][C@@H]1C=C(C(=O)OCC)C[C@@H](N)[C@H]1N=[W]</smiles><smiles>CCOC(=O)C1=C[C@H](OCc2ccc(Cl)c(Cl)c2)[C@H](N=[W])[C@H](N)C1</smiles>

Scheme 2

${ }^{13} \mathrm{C}$ NMR (125 MHz, $\left.\mathrm{CDCl}_{3}, \delta, \mathrm{ppm}\right): 13.6,14.2,21.9,23.6$, $29.4,31.5,31.9,46.6,50.8,55.2,60.9,128.9,139.3,165.9$, 171.9.

MS (ESI, $m / z): 315[\mathrm{M}+\mathrm{H}]^{+}$.

Ethyl (3R,4R,5S)-4-acetamido-5-amino-3-(phenylthio)cyclo hex-1-ene-1-carboxylate (4b): Color: White, amorphous solid. Yield: $85 \%$. $[\alpha]_{\mathrm{D}}{ }^{25}$ : -9.2 (c 0.17, $\mathrm{CHCl}_{3}$ ). ${ }^{1} \mathrm{H}$ NMR $(500 \mathrm{MHz}$, $\left.\mathrm{CDCl}_{3}, \delta, \mathrm{ppm}\right): 1.26\left(\mathrm{t}, J=7.0 \mathrm{~Hz}, 3 \mathrm{H}, \mathrm{CH}_{3}-2^{\prime}\right), 2.00(\mathrm{~s}, 3 \mathrm{H}, \mathrm{Ac})$, $2.03\left(\mathrm{~m}, 1 \mathrm{H}, \mathrm{H}_{\mathrm{a}}-6\right) ; 2.80\left(\mathrm{dd}, J=4.5,17.5 \mathrm{~Hz}, 1 \mathrm{H}, \mathrm{H}_{\mathrm{b}}-6\right), 3.17$ (ddd, $J=4.5,10.2,10.2 \mathrm{~Hz}, 1 \mathrm{H}, \mathrm{H}-5), 3.75$ (q, $J=10.2 \mathrm{~Hz}, 1 \mathrm{H}, \mathrm{H}-$ 4), 3.90 (br. d, $J=10.5 \mathrm{~Hz}, 1 \mathrm{H}, \mathrm{H}-3), 4.16\left(\mathrm{~m}, 2 \mathrm{H}, \mathrm{CH}_{2}-1^{\prime}\right.$ ), 6.27 (d, $J=10.2 \mathrm{~Hz}, 1 \mathrm{H}, \mathrm{NH}), 6.89$ (br. s, $1 \mathrm{H}, \mathrm{H}-2), 7.27-7.33$ (m, $3 \mathrm{ArH}, \mathrm{H}-3^{\prime \prime}, \mathrm{H}-4^{\prime \prime}$ and $\mathrm{H}-5^{\prime \prime}$ ), 7.46 (dd, $J=1.5,8.5 \mathrm{~Hz}, 2 \mathrm{ArH}, \mathrm{H}-2^{\prime \prime}$ and $\left.\mathrm{H}-6^{\prime \prime}\right) .{ }^{13} \mathrm{C}$ NMR (125 $\left.\mathrm{MHz} \mathrm{CDCl}_{3}, \delta, \mathrm{ppm}\right): 14.2,23.6,32.1$, $50.2,50.9,56.4,60.9,128.3,129.0,129.3,132.0,134.0,138.1$, 165.8, 171.6. MS (ESI, $m / z): 335[\mathrm{M}+\mathrm{H}]^{+}$.

Ethyl (3R,4R,5S)-4-acetamido-5-amino-3-(o-tolylthio)cyclo hex-1-ene-1-carboxylate (4c): Color: Yellow, amorphous solid. Yield: $83 \% .[\alpha]_{\mathrm{D}}{ }^{25}:-42.9(c) 0.14, \mathrm{CHCl}_{3}$ ). ${ }^{1} \mathrm{H}$ NMR $(500 \mathrm{MHz}$, $\left.\mathrm{CDCl}_{3}, \delta, \mathrm{ppm}\right): 1.26\left(\mathrm{t}, J=7.1 \mathrm{~Hz}, 3 \mathrm{H}, \mathrm{CH}_{3}-2^{\prime}\right), 1.96(\mathrm{~s}, 3 \mathrm{H}, \mathrm{Ac})$, $2.15\left(\mathrm{~m}, 1 \mathrm{H}, \mathrm{H}_{\mathrm{a}}-6\right), 2.43\left(\mathrm{~s}, 3 \mathrm{H}, \mathrm{CH}_{3}-7^{\prime \prime}\right), 2.82(\mathrm{dd}, J=4.5$ and $\left.17.5 \mathrm{~Hz}, 1 \mathrm{H}, \mathrm{H}_{\mathrm{b}}-6\right), 3.14$ (ddd, $J=4.5,9.5$ and $9.5 \mathrm{~Hz}, 1 \mathrm{H}, \mathrm{H}-5$ ), 3.80 (q, $J=9.5 \mathrm{~Hz}, 1 \mathrm{H}, \mathrm{H}-4), 3.93$ (br. d, $J=9.5 \mathrm{~Hz}, 1 \mathrm{H}, \mathrm{H}-3$ ), 4.15 (m, 2H, $\mathrm{CH}_{2}-1^{\prime}$ ), 6.07 (br. s, $1 \mathrm{H}, \mathrm{NH}$ ), 6.82 (br. s, 1H, H-2), 7.15 $\left(\mathrm{dt}, J=1.5,8.0 \mathrm{~Hz}, 1 \mathrm{H}, \mathrm{Ar}-\mathrm{H}-4^{\prime \prime}\right), 7.18(\mathrm{dt}, J=1.5,8.0 \mathrm{~Hz}, 1 \mathrm{H}, \mathrm{Ar}-$ $\mathrm{H}-5^{\prime \prime}$ ), 7.21 (dd, $J=1.5,8.0 \mathrm{~Hz}, 1 \mathrm{H}, \mathrm{Ar}-\mathrm{H}-3^{\prime \prime}$ ), 7.45 (dd, $J=1.5$, $\left.8.0 \mathrm{~Hz}, 1 \mathrm{H}, \mathrm{Ar}-\mathrm{H}-6^{\prime \prime}\right) .{ }^{13} \mathrm{C} \mathrm{NMR}\left(125 \mathrm{MHz}, \mathrm{CDCl}_{3}, \delta, \mathrm{ppm}\right): 14.1$, $20.9,23.5,32.5,49.6,50.9,57.4,60.9,126.6,128.0,129.0$, 130.7, 132.7, 133.2, 137.4, 140.6, 166.0, 171.4. MS (ESI, $m / z)$ : $349[\mathrm{M}+\mathrm{H}]^{+}$.

Ethyl (3R,4R,5S)-4-acetamido-5-amino-3-(ethylthio)cyclo hex-1-ene-1-carboxylate (4d): Color: Yellow, amorphous solid. Yield: $82 \% .[\alpha]_{\mathrm{D}} 25:-52.4\left(c \quad 0.55, \mathrm{CHCl}_{3}\right.$ ). ${ }^{1} \mathrm{H}$ NMR $(500 \mathrm{MHz}$, $\left.\mathrm{CDCl}_{3}, \delta, \mathrm{ppm}\right): 1.22\left(\mathrm{t}, J=7.5 \mathrm{~Hz}, 3 \mathrm{H}, \mathrm{CH}_{3}-2^{\prime \prime}\right), 1.29(\mathrm{t}, J=7.0 \mathrm{~Hz}$, $3 \mathrm{H}, \mathrm{CH}_{3}-2^{\prime}$ ), 2.09 (s, 3H, Ac), $2.24\left(\mathrm{~m}, 1 \mathrm{H}, \mathrm{H}_{\mathrm{a}}-6\right), 2.50\left(\mathrm{~m}, 1 \mathrm{H}, \mathrm{H}_{\mathrm{a}}-\right.$ $\left.1^{\prime \prime}\right), 2.58\left(\mathrm{~m}, 1 \mathrm{H}, \mathrm{Hb}_{\mathrm{b}} 1^{\prime \prime}\right), 2.85(\mathrm{~m}, 1 \mathrm{H}, \mathrm{Hb}-6), 3.19$ (ddd, $J=5.0$, 10.0, $10.0 \mathrm{~Hz}, 1 \mathrm{H}, \mathrm{H}-5$ ), 3.47 (br. s, $J=10.0 \mathrm{~Hz}, 1 \mathrm{H}, \mathrm{H}-3$ ), 3.83 (q, $J=10.0 \mathrm{~Hz}, 1 \mathrm{H}, \mathrm{H}-4), 4.20\left(\mathrm{q}, J=7.0 \mathrm{~Hz}, 2 \mathrm{H}, \mathrm{CH}_{2}-1^{\prime}\right), 6.40(\mathrm{~d}, J=$ $10.0 \mathrm{~Hz}, 1 \mathrm{H}, \mathrm{NH}), 6.88$ (br. s, $1 \mathrm{H}, \mathrm{H}-2) .{ }^{13} \mathrm{C}$ NMR (125 MHz, $\left.\mathrm{CDCl}_{3}, \delta, \mathrm{ppm}\right): 14.2,14.6,23.6,23.7,32.0,46.6,50.9,55.3,60.9$, $128.9,139.2,165.9,171.9$. MS (ESI, $m / z): 287[\mathrm{M}+\mathrm{H}]^{+}$.

Ethyl (3R,4R,5S)-4-acetamido-5-amino-3-(benzylthio) cyclo hex-1-ene-1-carboxylate (4e): Color: White, amorphous solid. Yield: $83 \%$. $[\alpha]_{\mathrm{D}}{ }^{25}$ : $-113.1\left(c 0.53, \mathrm{CHCl}_{3}\right) .{ }^{1} \mathrm{H}$ NMR $(500 \mathrm{MHz}$, $\left.\mathrm{CDCl}_{3}, \delta, \mathrm{ppm}\right): 1.27\left(\mathrm{t}, J=7.0 \mathrm{~Hz}, 3 \mathrm{H}, \mathrm{CH}_{3}-2^{\prime}\right), 2.05(\mathrm{~s}, 3 \mathrm{H}, \mathrm{Ac}$ ), $2.21\left(\mathrm{~m}, 1 \mathrm{H}, \mathrm{H}_{\mathrm{a}}-6\right), 2.84\left(\mathrm{dd}, J=4.5,17.5 \mathrm{~Hz}, 1 \mathrm{H}, \mathrm{H}_{\mathrm{b}}-6\right), 3.11$ (ddd, $J=4.5,10.0,10.0 \mathrm{~Hz}, 1 \mathrm{H}, \mathrm{H}-5$ ), 3.36 (br. d, $J=10.0 \mathrm{~Hz}, 1 \mathrm{H}$, $\mathrm{H}-3), 3.72$ (d, $J=13.0 \mathrm{~Hz}, 1 \mathrm{H}, \mathrm{H}_{\mathrm{a}}-1^{\prime \prime}$ ), $3.78\left(\mathrm{~d}, J=13.0 \mathrm{~Hz}, 1 \mathrm{H}, \mathrm{H}_{\mathrm{b}}-\right.$ $1^{\prime \prime}$ ), $3.90(\mathrm{q}, J=10.0 \mathrm{~Hz}, 1 \mathrm{H}, \mathrm{H}-4), 4.14\left(\mathrm{~m}, 2 \mathrm{H}, \mathrm{CH}_{2}-1^{\prime}\right.$ ), 6.10 (br. s, $1 \mathrm{H}, \mathrm{NH}$ ), 6.76 (br. s, $1 \mathrm{H}, \mathrm{H}-2), 7.21-7.31$ (m, 5H, Ar-H). ${ }^{13} \mathrm{C}$ NMR (125 MHz, $\mathrm{CDCl}_{3}, \delta$, ppm): 14.1, 23.6, 32.0, 34.5, 46.7, 51.0,
$54.9,60.9,127.2,128.5,128.7,129.1,137.7,138.8,165.8,171.8$. MS (ESI, $m / z): 349[\mathrm{M}+\mathrm{H}]^{+}$.

\subsubsection{General procedure for compounds $5 a-f$}

To a solution of compound $\mathbf{1}(0.6 \mathrm{mmol})$ and alcohols (4 eq.) in anhydrous $\mathrm{CH}_{2} \mathrm{Cl}_{2}(0.5 \mathrm{~mL})$ was added borontrifluoride diethyl etherate $(1.5 \mathrm{eq})$ in $\mathrm{CH}_{2} \mathrm{Cl}_{2}(0.5 \mathrm{~mL})$ at $-8{ }^{\circ} \mathrm{C}$. The reaction mixture was stirred for $1 \mathrm{~h}$. Aqueous solution of potassium carbonate $5 \%(15 \mathrm{~mL})$ was added and the mixture was extracted with $\mathrm{CH}_{2} \mathrm{Cl}_{2}(3 \times 15 \mathrm{~mL})$. The organic layers were combined, washed with water $(5 \mathrm{~mL})$ and concentrated under reduced pressure. The residue was chromatographed (nhexane:EtOAc gradient) to obtain compounds 5a-f (Scheme 2).

Ethyl (3R,4S,5R)-4-acetamido-3-(cyclohexylmethoxy)-5((methylsulfonyl)oxy)cyclohex-1-ene-1-carboxylate (5a): Color: White, amorphous solid. Yield: $55 \% .{ }^{1} \mathrm{H}$ NMR $\left(500 \mathrm{MHz}, \mathrm{CDCl}_{3}\right.$, $\delta, \mathrm{ppm}):$ 0.91-0.98 (m, 2H, cyclohexane), 1.15-1.30 (m, 3H, cyclohexane), $1.33\left(\mathrm{t}, J=7.1 \mathrm{~Hz}, 3 \mathrm{H}, \mathrm{CH}_{3}-2^{\prime}\right), 1.54-1.79(\mathrm{~m}, 6 \mathrm{H}$, cyclohexane), $2.05(\mathrm{~s}, 3 \mathrm{H}, \mathrm{Ac}), 2.75-2.87\left(\mathrm{~m}, 2 \mathrm{H}, \mathrm{CH}_{2}-6\right), 3.06(\mathrm{~s}$, $3 \mathrm{H}$, mesyl), 3.26 (dd, $J=6.5,8.5 \mathrm{~Hz}, 1 \mathrm{H}, \mathrm{H}_{\mathrm{a}}-1^{\prime \prime}$ ), 3.47 (dd, $J=6.5$, $8.5 \mathrm{~Hz}, 1 \mathrm{H}, \mathrm{H}_{\mathrm{b}}-2^{\prime \prime}$ ), 4.11 (dd, $J=1.5,9.0 \mathrm{~Hz}, 1 \mathrm{H}, \mathrm{H}-3$ ), 4.23 (q, $J=$ $7.1 \mathrm{~Hz}, 2 \mathrm{H}, \mathrm{CH}_{2}-1^{\prime}$ ), 4.33 (ddd, $J=2.0,8.0,9.0 \mathrm{~Hz}, 1 \mathrm{H}, \mathrm{H}-4$ ), 5.29 (m, 1H, H-5), 5.85 (d, $J=8.0 \mathrm{~Hz}, 1 \mathrm{H}, \mathrm{NH}), 6.96$ (br. s, $1 \mathrm{H}, \mathrm{H}-2$ ).

Ethyl (3R,4S,5R)-4-acetamido-3-(2-cyclohexylethoxy)-5((methylsulfonyl)oxy)cyclohex-1-ene-1-carboxylate (5b): Color:

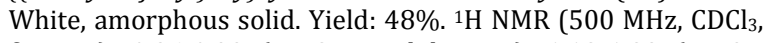
$\delta, \mathrm{ppm}): 0.86-0.93(\mathrm{~m}, 2 \mathrm{H}$, cyclohexane), 1.12-1.29 (m, 3H cyclohexane), $1.31\left(\mathrm{t}, J=7.1 \mathrm{~Hz}, 3 \mathrm{H}, \mathrm{CH}_{3}-2^{\prime}\right), 1.36-1.69(\mathrm{~m}, 8 \mathrm{H}$, cyclohexane and $\left.\mathrm{CH}_{2}-2^{\prime \prime}\right), 2.03(\mathrm{~s}, 3 \mathrm{H}, \mathrm{Ac}), 2.73-2.84(\mathrm{~m}, 2 \mathrm{H}$ $\left.\mathrm{CH}_{2}-6\right), 3.03$ (s, 3H, mesyl), $3.48\left(\mathrm{~m}, 1 \mathrm{H}, \mathrm{H}_{\mathrm{a}}-1^{\prime \prime}\right), 3.66\left(\mathrm{~m}, 1 \mathrm{H}, \mathrm{H}_{\mathrm{b}}\right.$ $1^{\prime \prime}$ ), $4.11(\mathrm{dd}, J=1.8,9.0 \mathrm{~Hz}, 1 \mathrm{H}, \mathrm{H}-3), 4.22(\mathrm{q}, J=7.1 \mathrm{~Hz}, 2 \mathrm{H}$, $\mathrm{CH}_{2}-1^{\prime}$ ), 4.30 (ddd, $\left.J=2.0,7.5,9.0 \mathrm{~Hz}, 1 \mathrm{H}, \mathrm{H}-4\right), 5.28(\mathrm{~m}, 1 \mathrm{H}, \mathrm{H}-$ 5), $5.84(\mathrm{~d}, J=7.5 \mathrm{~Hz}, 1 \mathrm{H}, \mathrm{NH}), 6.94(\mathrm{~s}, 1 \mathrm{H}, \mathrm{H}-2)$.

Ethyl (3R,4S,5R)-4-acetamido-3-(cycloheptyloxy)-5-((methyl sulfonyl)oxy)cyclohex-1-ene-1-carboxylate (5c): Color: White, Amorphous solid. Yield: $52 \%$. ${ }^{1} \mathrm{H}$ NMR $\left(500 \mathrm{MHz}, \mathrm{CDCl}_{3}, \delta\right.$, ppm): $1.30\left(\mathrm{t}, J=7.1 \mathrm{~Hz}, 3 \mathrm{H}, \mathrm{CH}_{3}-2^{\prime}\right), 1.32-1.39(\mathrm{~m}, 2 \mathrm{H}$, cycloheptane), 1.49-1.56 (m, 4H, cycloheptane), 1.58-1.65 (m, $6 \mathrm{H}$, cycloheptane), $2.02(\mathrm{~s}, 3 \mathrm{H}, \mathrm{Ac}), 2.69-2.74\left(\mathrm{~m}, 1 \mathrm{H}, \mathrm{H}_{\mathrm{a}}-6\right)$, 2.80-2.85 (m, 1H, $\left.\mathrm{H}_{\mathrm{b}}-6\right), 3.04$ (s, 3H, mesyl), $3.65\left(\mathrm{~m}, 1 \mathrm{H}, \mathrm{H}-1^{\prime \prime}\right)$, 4.07 (dd, $J=1.5,8.5 \mathrm{~Hz}, 1 \mathrm{H}, \mathrm{H}-3), 4.21\left(\mathrm{q}, J=7.1 \mathrm{~Hz}, 2 \mathrm{H}, \mathrm{CH}_{2}-1^{\prime}\right)$, 4.26 (m, 1H, H-4), 5.22 (m, 1H, H-5), 5.89 (br. s, 1H, NH), 6.96 (br. s, $1 \mathrm{H}, \mathrm{H}-2)$.

Ethyl $\quad(3 R, 4 S, 5 R)-4$-acetamido-3-isobutoxy-5-((methyl sulfonyl)oxy)cyclohex-1-ene-1-carboxylate (5d): Color: White, amorphous solid. Yield: $60 \% .{ }^{1} \mathrm{H}$ NMR $\left(500 \mathrm{MHz} \mathrm{CDCl}_{3}, \delta\right.$, ppm): $0.90\left(\mathrm{t}, J=6.5 \mathrm{~Hz}, 6 \mathrm{H}, \mathrm{CH}_{3}-3^{\prime \prime}\right.$ and $\left.\mathrm{CH}_{3}-4^{\prime \prime}\right), 1.31(\mathrm{t}, J=7.1$ $\mathrm{Hz}, 3 \mathrm{H}, \mathrm{CH}_{3}-2^{\prime}$ ), 1.83 (m, 1H, H-2'), 2.03 (s, 3H, Ac), 2.73-2.85 (m, $\left.2 \mathrm{H}, \mathrm{CH}_{2}-6\right), 3.04(\mathrm{~s}, 3 \mathrm{H}$, mesyl), 3.19 (dd, $J=6.5,8.5 \mathrm{~Hz}, 1 \mathrm{H}$, $\left.\mathrm{H}_{\mathrm{a}}-1^{\prime \prime}\right), 3.43$ (dd, $\left.J=6.5,8.5 \mathrm{~Hz}, 1 \mathrm{H}, \mathrm{Hb}-1^{\prime \prime}\right), 4.11(\mathrm{dd}, J=2.0,9.5$ $\mathrm{Hz}, 1 \mathrm{H}, \mathrm{H}-3$ ), 4.23 (q, J = $7.1 \mathrm{~Hz}, 2 \mathrm{H}, \mathrm{CH}_{2}-1^{\prime}$ ), 4.32 (m, 1H, H-4), 
5.27 (m, 1H, H-5), 5.85 (d, J = $8.0 \mathrm{~Hz}, 1 \mathrm{H}, \mathrm{NH}$ ), 6.94 (br. s, $1 \mathrm{H}, \mathrm{H}-$ 2).

Ethyl (3R,4S,5R)-4-acetamido-3-(4-fluorophenoxy)-5((methylsulfonyl)oxy)cyclohex-1-ene-1-carboxylate (5e): Color: White, amorphous solid. Yield: $75 \% .{ }^{1} \mathrm{H}$ NMR $\left(500 \mathrm{MHz}, \mathrm{CDCl}_{3}\right.$, $\delta$, ppm): 1.31 (t, $\left.J=7.0 \mathrm{~Hz}, 3 \mathrm{H}, \mathrm{CH}_{3}-2^{\prime}\right), 1.99$ (s, 3H, Ac), 2.78$2.83\left(\mathrm{~m}, 2 \mathrm{H}, \mathrm{CH}_{2}-6\right), 3.02$ (s, 3H, mesyl), 4.19-4.25 (m, 3H, $\mathrm{CH}_{2-}$ $1^{\prime}$ and H-3), 4.38 (ddd, $J=2.0,8.5,10.5 \mathrm{~Hz}, 1 \mathrm{H}, \mathrm{H}-4$ ), 4.52 (d, $J=$ $\left.11.5 \mathrm{~Hz}, 1 \mathrm{H}, \mathrm{H}_{\mathrm{a}}-1^{\prime \prime}\right), 4.67\left(\mathrm{~d}, J=11.5 \mathrm{~Hz}, 1 \mathrm{H}, \mathrm{H}_{\mathrm{b}}-1^{\prime \prime}\right), 5.25(\mathrm{~m}, 1 \mathrm{H}$, H-5), 5.80 (d, $J=8.5 \mathrm{~Hz}, 1 \mathrm{H}, \mathrm{NH}$ ), 6.95 (br. s, 1H, H-2), 7.04 (t, $J=$ $8.5 \mathrm{~Hz}, 2 \mathrm{H}, \mathrm{Ar}-\mathrm{H}-4^{\prime \prime}$ and $\left.\mathrm{H}-6^{\prime \prime}\right), 7.32$ (dd, $J=5.5,8.5 \mathrm{~Hz}, 2 \mathrm{H}, \mathrm{Ar}-$ $\mathrm{H}-3^{\prime \prime}$ and $\left.\mathrm{H}-7^{\prime \prime}\right)$.

Ethyl (3R,4S,5R)-4-acetamido-3-(3,4-dichlorophenoxy)-5((methylsulfonyl)oxy) cyclohex-1-ene-1-carboxylate (5f): Color: White, amorphous solid. Yield: $45 \% .{ }^{1} \mathrm{H}$ NMR $\left(500 \mathrm{MHz}, \mathrm{CDCl}_{3}\right.$, $\delta, \mathrm{ppm}): 1.31$ (t, $\left.J=7.0 \mathrm{~Hz}, 3 \mathrm{H}, \mathrm{CH}_{3}-2^{\prime}\right), 2.02$ (s, 3H, Ac), 2.76$2.83\left(\mathrm{~m}, 2 \mathrm{H}, \mathrm{CH}_{2}-6\right), 3.04\left(\mathrm{~s}, 3 \mathrm{H}\right.$, mesyl), 4.21-4.25 (m, 3H, $\mathrm{CH}_{2^{-}}$ $1^{\prime}$ and H-3), 4.42 (ddd, $J=2.5,8.0,10.0 \mathrm{~Hz}, 1 \mathrm{H}, \mathrm{H}-4$ ), 4.50 (d, $J=$ $\left.12.0 \mathrm{~Hz}, 1 \mathrm{H}, \mathrm{H}_{\mathrm{a}}-1^{\prime \prime}\right), 4.65\left(\mathrm{~d}, J=12.0 \mathrm{~Hz}, 1 \mathrm{H}, \mathrm{H}_{\mathrm{b}}-1^{\prime}\right), 5.23(\mathrm{~m}, 1 \mathrm{H}$, H-5), 5.99 (d, $J=8.0 \mathrm{~Hz}, 1 \mathrm{H}, \mathrm{NH}$ ), 6.93 (br. s, 1H, H-2), 7.15 (dd, $J$ $\left.=2.0,8.5 \mathrm{~Hz}, 1 \mathrm{H}, \mathrm{Ar}-\mathrm{H}-7^{\prime \prime}\right), 7.41\left(\mathrm{~d}, J=8.5 \mathrm{~Hz}, 1 \mathrm{H}, \mathrm{Ar}-\mathrm{H}-6^{\prime \prime}\right)$, $7.43\left(\mathrm{~d}, J=2.0 \mathrm{~Hz}, 1 \mathrm{H}, \mathrm{Ar}-\mathrm{H}-3^{\prime \prime}\right)$.

\subsubsection{General procedure for compounds $6 a-f$}

To a solution of compounds $\mathbf{5 a - f}(0.4 \mathrm{mmol})$ in a mixture of ethanol: $\mathrm{H}_{2} \mathrm{O}(5: 1, v: v, 5 \mathrm{~mL})$ was added sodium azide (3 eq.). The reaction solution was stirred for $8 \mathrm{~h}$ at reflux. The mixture was cooled to room temperature and water $(15 \mathrm{~mL})$ was added, then extracted with EtOAc $(3 \times 15 \mathrm{~mL})$. The EtOAc solution was dried over sodium sulphate, concentrated under reduced pressure and the residue was purified by silica gel column chromatography ( $n$-hexane:EtOAc gradient) to give compounds 6a-f (Scheme 2).

Ethyl (3R,4R,5S)-4-acetamido-5-azido-3-(cyclohexylmethoxy) cyclohex-1-ene-1-carboxylate (6a): Color: White, amorphous solid. Yield: $71 \%$. ${ }^{1} \mathrm{H}$ NMR (500 $\mathrm{MHz}, \mathrm{CDCl}_{3}, \delta, \mathrm{ppm}$ ): 0.90-0.97 (m, 2H, cyclohexane), 1.13-1.25 (m, 3H, cyclohexane), $1.31(\mathrm{t}, J$ $\left.=7.1 \mathrm{~Hz}, 3 \mathrm{H}, \mathrm{CH}_{3}-2^{\prime}\right), 1.54-1.76(\mathrm{~m}, 6 \mathrm{H}$, cyclohexane), $2.04(\mathrm{~s}$, $3 \mathrm{H}, \mathrm{Ac}), 2.26(\mathrm{~m}, 1 \mathrm{H}, \mathrm{Ha}-6), 2.86$ (dd, $J=5.0,17.0 \mathrm{~Hz}, 1 \mathrm{H}, \mathrm{Hb}-6)$, 3.24 (dd, $J=6.5,8.5 \mathrm{~Hz}, 1 \mathrm{H}, \mathrm{H}_{\mathrm{a}}-1^{\prime \prime}$ ), 3.45 (dd, $J=6.5,8.5 \mathrm{~Hz}, 1 \mathrm{H}$, $\left.\mathrm{Hb}_{\mathrm{b}} \mathrm{1}^{\prime \prime}\right), 3.54(\mathrm{~m}, 1 \mathrm{H}, \mathrm{H}-3), 4.12(\mathrm{~m}, 1 \mathrm{H}, \mathrm{H}-4), 4.22$ (q, J = $7.1 \mathrm{~Hz}$, $\left.2 \mathrm{H}, \mathrm{CH}_{2}-1^{\prime}\right), 4.43(\mathrm{~m}, 1 \mathrm{H}, \mathrm{H}-5), 5.61(\mathrm{~d}, J=8.0 \mathrm{~Hz}, 1 \mathrm{H}, \mathrm{NH}), 6.84$ (s, 1H, H-2).

Ethyl (3R,4R,5S)-4-acetamido-5-azido-3-(2-cyclohexyl ethoxy)cyclohex-1-ene-1-carboxylate (6b): Color: Yellow, amorphous solid. Yield: $88 \% .{ }^{1} \mathrm{H}$ NMR $\left(500 \mathrm{MHz}, \mathrm{CDCl}_{3}, \delta\right.$, ppm): 0.86-0.93 (m, 2H, cyclohexane), 1.12-1.27 (m, 3H, cyclohexane), $1.30\left(\mathrm{t}, J=7.1 \mathrm{~Hz}, 3 \mathrm{H}, \mathrm{CH}_{3}-2^{\prime}\right), 1.34-1.69(\mathrm{~m}, 8 \mathrm{H}$, cyclohexane and $\left.\mathrm{CH}_{2}-2^{\prime \prime}\right), 2.05(\mathrm{~s}, 3 \mathrm{H}, \mathrm{Ac}), 2.26\left(\mathrm{~m}, 1 \mathrm{H}, \mathrm{H}_{\mathrm{a}}-6\right)$, $2.86\left(\mathrm{dd}, J=5.5,17.5 \mathrm{~Hz}, 1 \mathrm{H}, \mathrm{H}_{\mathrm{b}}-6\right), 3.46-3.54\left(\mathrm{~m}, 2 \mathrm{H}, \mathrm{CH}_{2}-1^{\prime \prime}\right)$, 3.67 (m, 1H, H-3), $4.14(\mathrm{~m}, 1 \mathrm{H}, \mathrm{H}-4), 4.21$ (q, J= $7.1 \mathrm{~Hz}, 2 \mathrm{H}, \mathrm{CH}_{2-}$ $\left.1^{\prime}\right), 4.45(\mathrm{~m}, 1 \mathrm{H}, \mathrm{H}-5), 5.67$ (d, $\left.J=8.0 \mathrm{~Hz}, 1 \mathrm{H}, \mathrm{NH}\right), 6.84$ (br. s, $1 \mathrm{H}, \mathrm{H}-2)$.

Ethyl (3R,4R,5S)-4-acetamido-5-azido-3-(cycloheptyloxy) cyclohex-1-ene-1-carboxylate (6c): Color: White, amorphous solid. Yield: $53 \% .{ }^{1} \mathrm{H}$ NMR $\left(500 \mathrm{MHz}, \mathrm{CDCl}_{3}, \delta, \mathrm{ppm}\right): 1.30(\mathrm{t}, J=$ 7.1 Hz, $3 \mathrm{H}, \mathrm{CH}_{3}-2^{\prime}$ ), 1.31-1.41 (m, 2H, cycloheptane), 1.49-1.66 (m, 8H, cycloheptane), 1.79-1.90 (m, 2H, cycloheptane), $2.03(\mathrm{~s}$, $3 \mathrm{H}, \mathrm{Ac}), 2.22\left(\mathrm{~m}, 1 \mathrm{H}, \mathrm{H}_{\mathrm{a}}-6\right), 2.85$ (dd, J = 5.7, $17.5 \mathrm{~Hz}, 1 \mathrm{H}, \mathrm{H}_{\mathrm{b}}-6$ ), $3.26(\mathrm{~m}, 1 \mathrm{H}, \mathrm{H}-3), 3.62\left(\mathrm{~m}, 1 \mathrm{H}, \mathrm{H}-1^{\prime \prime}\right), 4.21(\mathrm{q}, J=7.1 \mathrm{~Hz}, 2 \mathrm{H}$, $\left.\mathrm{CH}_{2}-1^{\prime}\right), 4.32(\mathrm{~m}, 1 \mathrm{H}, \mathrm{H}-4), 4.56(\mathrm{~m}, 1 \mathrm{H}, \mathrm{H}-5), 5.71(\mathrm{~d}, J=7.0 \mathrm{~Hz}$, $1 \mathrm{H}, \mathrm{NH}), 6.77$ (s, $1 \mathrm{H}, \mathrm{H}-2) .{ }^{13} \mathrm{C}$ NMR (125 MHz, $\left.\mathrm{CDCl}_{3}, \delta, \mathrm{ppm}\right):$ 14.1, 22.5, 23.2, 23.9, 28.2, 29.8, 34.2, 34.9, 38.5, 51.6, 61.1, $72.2,78.0,80.0,127.4,137.0,165.7,170.6$.

Ethyl (3R,4R,5S)-4-acetamido-5-azido-3-isobutoxycyclohex1-ene-1-carboxylate $(\mathbf{6 d})$ : Color: Yellow, amorphous solid. Yield: $57 \% .{ }^{1} \mathrm{H}$ NMR (500 MHz, $\left.\mathrm{CDCl}_{3}, \delta, \mathrm{ppm}\right): 0.88(\mathrm{~d}, J=6.5 \mathrm{~Hz}, 3 \mathrm{H}$, $\left.\mathrm{CH}_{3}-3^{\prime \prime}\right), 0,89\left(\mathrm{~d}, J=6.5 \mathrm{~Hz}, 3 \mathrm{H}, \mathrm{CH}_{3}-4^{\prime \prime}\right), 1.29(\mathrm{t}, J=7.1 \mathrm{~Hz}, 3 \mathrm{H}$, $\mathrm{CH}_{3}-2^{\prime}$ ), 1.79 (m, 1H, H-2"), 2.03 (s, 3H, Ac), 2.25 (m, 1H, Ha), $2.85\left(\mathrm{dd}, J=5.5,17.5 \mathrm{~Hz}, 1 \mathrm{H}, \mathrm{H}_{\mathrm{b}}-6\right), 3.17$ (dd, $J=6.5,9.0 \mathrm{~Hz}, 1 \mathrm{H}$,
$\mathrm{H}_{\mathrm{a}}-1^{\prime \prime}$ ), 3.42 (dd, $J=6.5,9.0 \mathrm{~Hz}, 1 \mathrm{H}, \mathrm{H}_{\mathrm{b}}-1^{\prime \prime}$ ), 3.60 (m, $\left.1 \mathrm{H}, \mathrm{H}-3\right)$, $4.05(\mathrm{~m}, 1 \mathrm{H}, \mathrm{H}-4), 4.20$ (q, J = 7.1 Hz, 2H, $\left.\mathrm{CH}_{2}-\mathrm{1}^{\prime}\right), 4.39(\mathrm{~m}, 1 \mathrm{H}$, $\mathrm{H}-5), 5.93(\mathrm{~d}, J=8.0 \mathrm{~Hz}, 1 \mathrm{H}, \mathrm{NH}), 6.83(\mathrm{t}, J=2.0 \mathrm{~Hz}, 1 \mathrm{H}, \mathrm{H}-2)$.

Ethyl (3R,4R,5S)-4-acetamido-5-azido-3-(4-fluorophenoxy) cyclohex-1-ene-1-carboxylate (6e): Color: Yellow, amorphous solid. Yield: $56 \% .{ }^{1} \mathrm{H}$ NMR $\left(500 \mathrm{MHz}, \mathrm{CDCl}_{3}, \delta, \mathrm{ppm}\right): 1.30(\mathrm{t}, J=$ $7.0 \mathrm{~Hz}, 3 \mathrm{H}, \mathrm{CH}_{3}-2^{\prime}$ ), 1.99 (s, 3H, Ac), 2.28 (m, 1H, $\left.\mathrm{H}_{\mathrm{a}}-6\right), 2.88$ (dd, $\left.J=5.5,17.5 \mathrm{~Hz}, 1 \mathrm{H}, \mathrm{H}_{\mathrm{b}}-6\right), 3.62(\mathrm{~m}, 1 \mathrm{H}, \mathrm{H}-3), 4.08$ (m, 1H, H-4), $4.22\left(\mathrm{q}, J=7.0 \mathrm{~Hz}, 2 \mathrm{H}, \mathrm{CH}_{2}-1^{\prime}\right), 4.49\left(\mathrm{~d}, J=11.5 \mathrm{~Hz}, 1 \mathrm{H}, \mathrm{H}_{\mathrm{a}}-1^{\prime \prime}\right)$, $4.54(\mathrm{~m}, 1 \mathrm{H}, \mathrm{H}-5), 4.67$ (d, J=11.5 Hz, $\left.1 \mathrm{H}, \mathrm{H}_{\mathrm{b}}-\mathrm{1}^{\prime \prime}\right), 5.60$ (d, $J=7.5$ $\mathrm{Hz}, 1 \mathrm{H}, \mathrm{NH}), 6.86(\mathrm{~d}, J=2.0 \mathrm{~Hz}, 1 \mathrm{H}, \mathrm{H}-2), 7.02(\mathrm{t}, J=8.5 \mathrm{~Hz}, 2 \mathrm{H}$, Ar-H-4" and H-6"), 7.29 (dd, $J=5.5,8.5 \mathrm{~Hz}, 2 \mathrm{H}, \mathrm{Ar}-\mathrm{H}-3^{\prime \prime}$ and $\mathrm{H}-$ $\left.7^{\prime \prime}\right)$.

Ethyl (3R,4R,5S)-4-acetamido-5-azido-3-(3,4-dichloro phenoxy)cyclohex-1-ene-1-carboxylate (6f): Color: Yellow, amorphous solid. Yield: $47 \% .{ }^{1} \mathrm{H}$ NMR $\left(500 \mathrm{MHz}, \mathrm{CDCl}_{3}, \delta\right.$, ppm): $1.31\left(\mathrm{t}, J=7.0 \mathrm{~Hz}, 3 \mathrm{H}, \mathrm{CH}_{3}-2^{\prime}\right), 2.02(\mathrm{~s}, 3 \mathrm{H}, \mathrm{Ac}), 2.30(\mathrm{~m}$, $\left.1 \mathrm{H}, \mathrm{H}_{\mathrm{a}}-6\right), 2.90$ (dd, $\left.J=5.5,17.5 \mathrm{~Hz}, 1 \mathrm{H}, \mathrm{Hb}-6\right), 3.62(\mathrm{~m}, 1 \mathrm{H}, \mathrm{H}-3)$, $4.10(\mathrm{~m}, 1 \mathrm{H}, \mathrm{H}-4), 4.22\left(\mathrm{q}, J=7.0 \mathrm{~Hz}, 2 \mathrm{H}, \mathrm{CH}_{2}-1^{\prime}\right), 4.48(\mathrm{~d}, J=$ $\left.12.0 \mathrm{~Hz}, 1 \mathrm{H}, \mathrm{H}_{\mathrm{a}}-1^{\prime \prime}\right), 4.56$ (m, 1H, H-5), 4.67 (d, $J=12.0 \mathrm{~Hz}, 1 \mathrm{H}$, $\left.\mathrm{H}_{\mathrm{b}}-1^{\prime \prime}\right), 5.60(\mathrm{~d}, J=8.0 \mathrm{~Hz}, 1 \mathrm{H}, \mathrm{NH}), 6.86(\mathrm{t}, J=2.0 \mathrm{~Hz}, 1 \mathrm{H}, \mathrm{H}-2)$ 7.15 (dd, $\left.J=1.7,8.2 \mathrm{~Hz}, 1 \mathrm{H}, \mathrm{Ar}-\mathrm{H}-7^{\prime \prime}\right), 7.42$ (d, $J=8.2 \mathrm{~Hz}, 1 \mathrm{H}, \mathrm{Ar}-$ H-6"), 7.44 (d, $J=1.7 \mathrm{~Hz}, 1 \mathrm{H}, \mathrm{Ar}-\mathrm{H}-3^{\prime \prime}$ ).

\subsubsection{General procedure for synthesis of compound 7a-f}

A mixture of compounds 6 a-f $(0.1 \mathrm{mmol})$ and $\mathrm{Ph}_{3} \mathrm{P}$ (2 eq.) in THF: $\mathrm{H}_{2} \mathrm{O}(10: 1, v: v)$ was heated at $50{ }^{\circ} \mathrm{C}$ for $16 \mathrm{~h}$. The mixture solution was concentrated to dryness and the residue was purified by column chromatography on silica gel, eluted with $n$ hexane:EtOAc gradient, affording compounds 7a-f (Scheme 2).

Ethyl $\quad(3 R, 4 R, 5 S)$-4-acetamido-5-amino-3-(cyclohexyl methoxy)cyclohex-1-ene-1-carboxylate (7a): Color: Yellow, amorphous solid. Yield: $89 \%$. $[\alpha]_{\mathrm{D}^{25}}$ : $-74.8\left(\mathrm{c} 1.4, \mathrm{CHCl}_{3}\right) .{ }^{1} \mathrm{H}$ NMR (500 MHz, $\left.\mathrm{CDCl}_{3}, \delta, \mathrm{ppm}\right):$ 0.78-0.85 (m, 2H, cyclohexane), 1.03-1.14 (m, 3H, cyclohexane), $1.20\left(\mathrm{t}, J=7.0 \mathrm{~Hz}, 3 \mathrm{H}, \mathrm{CH}_{3}-2^{\prime}\right)$, 1.39-1.45 (m, 1H, cyclohexane), 1.66 (m, 5H, cyclohexane), 1.93 (s, 3H, Ac), $2.05\left(\mathrm{~m}, 1 \mathrm{H}, \mathrm{H}_{\mathrm{a}}-6\right), 2.67$ (dd, $J=5.0,17.5 \mathrm{~Hz}, 1 \mathrm{H}, \mathrm{Hb}^{-}$ 6), $2.83(\mathrm{~m}, 1 \mathrm{H}, \mathrm{H}-5), 3.09$ (dd, $\left.J=6.5,8.5 \mathrm{~Hz}, 1 \mathrm{H}, \mathrm{H}_{\mathrm{a}}-1^{\prime \prime}\right), 3.33$ (dd, $\left.J=6.5,8.5 \mathrm{~Hz}, 1 \mathrm{H}, \mathrm{Hb}-1^{\prime \prime}\right), 3.67$ (m, 1H, H-4), 3.95 (m, 1H, H3), 4.11 (q, J = 7.0 Hz, 2H, CHz-1'), 6.23 (br. s, 1H, NH), 6.71 (br. $\mathrm{s}, 1 \mathrm{H}, \mathrm{H}-2)$. MS (ESI, $m / z): 339[\mathrm{M}+\mathrm{H}]^{+}$.

Ethyl (3R,4R,5S)-4-acetamido-5-amino-3-(2-cyclohexyl ethoxy)cyclohex-1-ene-1-carboxylate (7b): Color: Yellow, amorphous solid. Yield: $92 \%$. $[\alpha]_{\mathrm{D}}{ }^{25}$ : $-26.4\left(c 0.83, \mathrm{CHCl}_{3}\right) .{ }^{1} \mathrm{H}$ NMR (500 MHz, $\left.\mathrm{CDCl}_{3}, \delta, \mathrm{ppm}\right): 0.80-0.87(\mathrm{~m}, 2 \mathrm{H}$, cyclohexane), 1.07-1.20 (m, 3H, cyclohexane), $1.35\left(\mathrm{t}, J=7.0 \mathrm{~Hz}, 3 \mathrm{H}, \mathrm{CH}_{3}-2^{\prime}\right)$, 1.30-1.36 (m, $\left.2 \mathrm{H}, \mathrm{CH}_{2}-2^{\prime \prime}\right), 1.37$ (m, $1 \mathrm{H}$, cyclohexane), 1.57-1.64 (m, 5H, cyclohexane), 1.99 (s, 3H, Ac), $2.09\left(\mathrm{~m}, 1 \mathrm{H}, \mathrm{H}_{\mathrm{a}}-6\right), 2.21$ (br. s, $\left.2 \mathrm{H}, \mathrm{NH}_{2}\right), 2.74\left(\mathrm{dd}, J=5.0,17.5 \mathrm{~Hz}, 1 \mathrm{H}, \mathrm{H}_{\mathrm{b}}-6\right), 2.99(\mathrm{~m}, 1 \mathrm{H}$, $\mathrm{H}-5), 3.39\left(\mathrm{~m}, 1 \mathrm{H}, \mathrm{H}_{\mathrm{a}}-1^{\prime \prime}\right), 3.58\left(\mathrm{~m}, 1 \mathrm{H}, \mathrm{H}_{\mathrm{b}}-1^{\prime \prime}\right), 3.70(\mathrm{~m}, 1 \mathrm{H}, \mathrm{H}-4)$, 4.05 (m, 1H, H-3), 4.15 (q, J = 7.0 Hz, 2H, CHz-1'), 6.20 (br. s, $1 \mathrm{H}$, $\mathrm{NH}), 6.76$ (br. s, $1 \mathrm{H}, \mathrm{H}-2) .{ }^{13} \mathrm{C}$ NMR $\left(125 \mathrm{MHz}, \mathrm{CDCl}_{3}, \delta, \mathrm{ppm}\right)$ : 13.9, 22.7, 25.6, 25.6, 26.3, 29.6, 29.7, 33.0, 38.0, 49.2, 55.8, 60.9, 74.5, 77.1, 129.7, 137.1, 166.1, 172.2. MS (ESI, $m / z): 353$ $[\mathrm{M}+\mathrm{H}]^{+}$.

Ethyl (3R,4R,5S)-4-acetamido-5-amino-3-(cycloheptyloxy) cyclohex-1-ene-1-carboxylate (7c): Color: Yellow, amorphous solid. Yield: $93 \%$. $[\alpha]_{\mathrm{D}}{ }^{25}$ : $-88.8\left(c 1.25, \mathrm{CHCl}_{3}\right) .{ }^{1} \mathrm{H}$ NMR $(500$ $\left.\mathrm{MHz}, \mathrm{CDCl}_{3}, \delta, \mathrm{ppm}\right): 1.26\left(\mathrm{t}, J=7.0 \mathrm{~Hz}, 3 \mathrm{H}, \mathrm{CH}_{3}-2^{\prime}\right), 1.32(\mathrm{~m}, 2 \mathrm{H}$, cycloheptane), 1.49-1.59 (m, 8H, cycloheptane), 1.76-1.92 (m, $2 \mathrm{H}$, cycloheptane), $2.00(\mathrm{~s}, 3 \mathrm{H}, \mathrm{Ac}), 2.10\left(\mathrm{~m}, 1 \mathrm{H}, \mathrm{H}_{\mathrm{a}}-6\right), 2.71$ (dd, $\left.J=5.0,17.5 \mathrm{~Hz}, 1 \mathrm{H}, \mathrm{H}_{\mathrm{b}}-6\right), 3.16\left(\mathrm{~m}, 1 \mathrm{H}, \mathrm{H}-1^{\prime \prime}\right), 3.48(\mathrm{~m}, 1 \mathrm{H}, \mathrm{H}-5)$, $3.58\left(\mathrm{~m}, 1 \mathrm{H}, \mathrm{H}-3\right.$ ), 4.17-4.19 (m, 3H, $\mathrm{H}-4$ and $\left.\mathrm{CH}_{2}-1^{\prime}\right), 6.02$ (br. s, $1 \mathrm{H}, \mathrm{NH}), 6.72$ (br. s, $1 \mathrm{H}, \mathrm{H}-2) .{ }^{13} \mathrm{C}$ NMR $\left(125 \mathrm{MHz}, \mathrm{CDCl}_{3}, \delta\right.$, ppm): 14.1, 22.6, 22.6, 23.5, 28.3, 28.3, 33.4, 33.9, 34.9, 35.0, 49.0, 60.8, 74.6, 79.4, 79.6, 129.4, 137.6, 166.2, 172.3. MS (ESI, $m / z): 339[\mathrm{M}+\mathrm{H}]^{+}$.

Ethyl (3R,4R,5S)-4-acetamido-5-amino-3-isobutoxycyclohex1-ene-1-carboxylate (7d): Color: Yellow, amorphous solid. Yield: 89\%. $[\alpha]_{\mathrm{D}}{ }^{25}:-4.8\left(c \mathrm{0} .67, \mathrm{CHCl}_{3}\right)$. 
Table 1. Cytotoxic activity of compounds $4 \mathbf{a}-\mathbf{f}$ and $\mathbf{7 a - f}$.

\begin{tabular}{|c|c|c|c|c|c|c|c|}
\hline \multirow[t]{2}{*}{ Compounds } & \multicolumn{3}{|c|}{$\mathrm{IC}_{50}(\mu \mathrm{g} / \mathrm{mL})$} & \multirow[t]{2}{*}{ Compounds } & \multicolumn{3}{|c|}{$\mathrm{IC}_{50}(\mu \mathrm{g} / \mathrm{mL})$} \\
\hline & KB & MCF-7 & LU-1 & & KB & MCF-7 & LU-1 \\
\hline$\overline{4 a}$ & 72.0 & 38.2 & 40.1 & $7 \mathrm{c}$ & 98.7 & 97.6 & 99.8 \\
\hline $4 \mathrm{~b}$ & 9.6 & 8.0 & 8.8 & $7 d$ & $>100$ & $>100$ & $>100$ \\
\hline $4 \mathrm{c}$ & 39.7 & 42.9 & 45.0 & $7 e$ & 84.6 & 72.7 & 74.1 \\
\hline $4 \mathrm{~d}$ & $>100$ & $>100$ & $>100$ & $7 f$ & 15.7 & 15.0 & 15.3 \\
\hline $4 \mathrm{e}$ & 79.7 & 62.5 & 82.9 & Ellipticine & 1.1 & 0.9 & 0.9 \\
\hline $7 a$ & 84.9 & 80.0 & 79.7 & Oseltamivir phosphate & $>100$ & $>100$ & $>100$ \\
\hline $7 \mathrm{~b}$ & 27.6 & 24.1 & 25.8 & & & & \\
\hline
\end{tabular}

${ }^{1} \mathrm{H}$ NMR (500 MHz, $\left.\mathrm{CDCl}_{3}, \delta, \mathrm{ppm}\right): 0.84(\mathrm{~d}, J=6.5 \mathrm{~Hz}, 3 \mathrm{H}$, $\left.\mathrm{CH}_{3}-3^{\prime \prime}\right), 0.88\left(\mathrm{~d}, J=6.5 \mathrm{~Hz}, 3 \mathrm{H}, \mathrm{CH}_{3}-4^{\prime \prime}\right), 1.27(\mathrm{t}, J=7.0 \mathrm{~Hz}, 3 \mathrm{H}$, $\mathrm{CH}_{3}-2^{\prime}$ ), 1.77 (m, 1H, H-2"), 2.01 (s, 3H, Ac), $2.12\left(\mathrm{~m}, 1 \mathrm{H}, \mathrm{H}_{\mathrm{a}}-6\right)$, $2.75\left(\mathrm{dd}, J=5.0,17.5 \mathrm{~Hz}, 1 \mathrm{H}, \mathrm{H}_{\mathrm{b}}-6\right), 2.99(\mathrm{~m}, 1 \mathrm{H}, \mathrm{H}-5), 3.10$ (dd, $J$ $\left.=8.0,15.0 \mathrm{~Hz}, 1 \mathrm{H}, \mathrm{H}_{\mathrm{a}}-1^{\prime \prime}\right), 3.36\left(\mathrm{dd}, J=8.0,15.0 \mathrm{~Hz}, 1 \mathrm{H}, \mathrm{Hb}-1^{\prime \prime}\right)$, $3.74(\mathrm{q}, J=9.0 \mathrm{~Hz}, 1 \mathrm{H}, \mathrm{H}-4), 4.06(\mathrm{~m}, 1 \mathrm{H}, \mathrm{H}-3), 4.17(\mathrm{q}, J=6.5$ $\mathrm{Hz}, 2 \mathrm{H}, \mathrm{CH}_{2}-1^{\prime}$ ), 6.03 (br. s, $1 \mathrm{H}, \mathrm{NH}$ ), 6.79 (br. s, $1 \mathrm{H}, \mathrm{H}-2$ ). ${ }^{13} \mathrm{C}$ NMR (125 MHz, $\left.\mathrm{CDCl}_{3}, \delta, \mathrm{ppm}\right): 14.0,19.0,19.2,23.0,28.6,33.3$, 49.2, 55.9, 60.9, 75.2, 80.8, 129.9, 137.1, 166.1, 172.3. MS (ESI, $m / z): 298[\mathrm{M}+\mathrm{H}]^{+}$.

Ethyl (3R,4R,5S)-4-acetamido-5-amino-3-(4-fluorophenoxy) cyclohex-1-ene-1-carboxylate (7e): Color: Yellow, amorphous solid. Yield: $88 \%$. $[\alpha]_{\mathrm{D}}{ }^{25}$ : $-38.75\left(c 0.5, \mathrm{CHCl}_{3}\right) .{ }^{1} \mathrm{H}$ NMR $(500$ $\left.\mathrm{MHz}, \mathrm{CDCl}_{3}, \delta, \mathrm{ppm}\right): 1.16\left(\mathrm{t}, J=7.0 \mathrm{~Hz}, 3 \mathrm{H}, \mathrm{CH}_{3}-2^{\prime}\right), 1.86(\mathrm{~s}, 3 \mathrm{H}$, Ac), $2.03\left(\mathrm{~m}, 1 \mathrm{H}, \mathrm{H}_{\mathrm{a}}-6\right), 2.65\left(\mathrm{dd}, J=5.0,17.5 \mathrm{~Hz}, 1 \mathrm{H}, \mathrm{H}_{\mathrm{b}}-6\right), 2.75$ (m, 1H, H-5), $3.71(\mathrm{q}, J=9.0 \mathrm{~Hz}, 1 \mathrm{H}, \mathrm{H}-4), 4.03(\mathrm{~m}, 1 \mathrm{H}, \mathrm{H}-3)$, $4.08\left(\mathrm{q}, J=7.0 \mathrm{~Hz}, 2 \mathrm{H}, \mathrm{CH}_{2}-1^{\prime}\right), 4.34\left(\mathrm{~d}, J=11.5 \mathrm{~Hz}, 1 \mathrm{H}, \mathrm{H}_{\mathrm{a}}-1^{\prime \prime}\right)$, $4.50\left(\mathrm{~d}, J=11.5 \mathrm{~Hz}, 1 \mathrm{H}, \mathrm{Hb}_{\mathrm{b}} 1^{\prime \prime}\right.$ ), 6.63 (br. s, $\left.1 \mathrm{H}, \mathrm{NH}\right), 6.72$ (br. s, $1 \mathrm{H}, \mathrm{H}-2), 6.89\left(\mathrm{t}, J=8.5 \mathrm{~Hz}, 2 \mathrm{H}, \mathrm{Ar}-\mathrm{H}-4^{\prime \prime}\right.$ and $\left.\mathrm{H}-6^{\prime \prime}\right), 7.17$ (dd, $J=$ 5.5, 8.5 Hz, 2H, Ar-H-3" and $\left.\mathrm{H}-7^{\prime \prime}\right) .{ }^{13} \mathrm{C}$ NMR $\left(125 \mathrm{MHz}, \mathrm{CDCl}_{3}, \delta\right.$, ppm): 14.1, 23.5, 33.8, 49.8, 56.7, 60.9, 69.4, 76.4, 115.2, 115.3, $129.7,129.8,130.9,133.6,136.1,161.4$ and 163.3 (C-F), 165.9, 171.0. MS (ESI, $m / z): 351.0[\mathrm{M}+\mathrm{H}]^{+}$.

Ethyl $\quad(3 R, 4 R, 5 S)$-4-acetamido-5-amino-3-(3,4-dichloro phenoxy)cyclohex-1-ene-1-carboxylate (7f): Color: White, amorphous solid. Yield: $68 \%$. $[\alpha]_{\mathrm{D}}{ }^{25}$ : $-50.8\left(c 1.0, \mathrm{CHCl}_{3}\right) .{ }^{1} \mathrm{H}$ NMR (500 MHz, $\left.\mathrm{CDCl}_{3}, \delta, \mathrm{ppm}\right): 1.30\left(\mathrm{t}, J=7 \mathrm{~Hz}, 3 \mathrm{H}, \mathrm{CH}_{3}-2^{\prime}\right)$, $2.04(\mathrm{~s}, 3 \mathrm{H}, \mathrm{Ac}), 2.18\left(\mathrm{~m}, 1 \mathrm{H}, \mathrm{H}_{\mathrm{a}}-6\right), 2.81(\mathrm{dd}, J=5.0,17.5 \mathrm{~Hz}, 1 \mathrm{H}$, $\left.\mathrm{H}_{\mathrm{b}}-6\right), 3.04(\mathrm{~m}, 1 \mathrm{H}, \mathrm{H}-5), 3.85$ (q, $\left.J=9.0 \mathrm{~Hz}, 1 \mathrm{H}, \mathrm{H}-4\right), 4.22$ (m, $3 \mathrm{H}, \mathrm{CH}_{2}-1^{\prime}$ and $\left.\mathrm{H}-3\right), 4.44\left(\mathrm{~d}, J=12.0 \mathrm{~Hz}, 1 \mathrm{H}, \mathrm{H}_{\mathrm{a}}-1^{\prime \prime}\right), 4.65(\mathrm{~d}, J=$ $12.0 \mathrm{~Hz}, 1 \mathrm{H}, \mathrm{H}_{\mathrm{b}}-1^{\prime \prime}$ ), 5.41 (d, $J=9.0 \mathrm{~Hz}, 1 \mathrm{H}, \mathrm{NH}$ ), 6.85 (br. s, $1 \mathrm{H}$, $\mathrm{H}-2$ ), 7.15 (dd, $\left.J=1.5,8.0 \mathrm{~Hz}, 1 \mathrm{H}, \mathrm{Ar}-\mathrm{H}_{-1} \mathbf{7}^{\prime}\right), 7.41$ (d, $J=8.0 \mathrm{~Hz}$, $\left.1 \mathrm{H}, \mathrm{Ar}-\mathrm{H}-6^{\prime \prime}\right), 7.45$ (d, $\left.J=1.5 \mathrm{~Hz}, 1 \mathrm{H}, \mathrm{Ar}-\mathrm{H}-3^{\prime \prime}\right) .{ }^{13} \mathrm{C}$ NMR $(125$ $\mathrm{MHz}, \mathrm{CDCl}_{3}, \delta$, ppm): 14.1, 23.5, 33.9, 49.7, 56.3, 61.0, 68.5, 76.8, $126.9,129.6,130.3,131.2,131.7,132.5,135.6,138.2,165.9$, 171.0. MS (ESI, $m / z): 401[\mathrm{M}+\mathrm{H}]^{+}$.

\subsection{Cytotoxicity assay}

The cancer cells (KB, MCF-7 and LU-1) were maintained in Dulbecco's D-MEM medium, supplemented with $10 \%$ fetal calf serum, L-glutamine $(2 \mathrm{mM})$, penicillin $\mathrm{G}(100 \mathrm{UI} / \mathrm{mL})$, streptomycin $(100 \mu \mathrm{g} / \mathrm{mL})$ and gentamicin $(10 \mu \mathrm{g} / \mathrm{mL})$. Stock solutions of compounds were prepared in DMSO/ $\mathrm{H}_{2} \mathrm{O}(1 / 9)$, and cytotoxicity assays were carried out in 96-well microtiter plates against KB, MCF-7 and LU-1 cancer cell lines $(3 \times$ $10^{3}$ cells $/ \mathrm{mL}$ ) using a modification of the published method [18]. After $72 \mathrm{~h}$ incubation at $37{ }^{\circ} \mathrm{C}$ in air/ $/ \mathrm{CO}_{2}$ (95:5) with or without test compounds, cell growth was estimated by colorimetric measurement of stained living cells by neutral red. Optical density was determined at $540 \mathrm{~nm}$ with a Titertek Multiscan photometer. The $\mathrm{IC}_{50}$ value was defined as the concentration of sample necessary to inhibit the cell growth to $50 \%$ of the control. Ellipticine was used as a reference compound.

\section{Results and discussion}

The synthesis of oseltamivir was previously described starting from shikimic acid, in which the synthesis via aziridine intermediate was considered to be an effective method $[19,20]$. The approach in this work is preparation of ether sulfur or ether oxygen at C-3 position of oseltamivir analogues based on ring opening of aziridine compound by different thiols or alcohols. Accordingly, aziridine $\mathbf{1}$ was obtained from shikimic acid through five steps in high yields using previous reported methods $[19,20]$.

Aziridines are highly strained, three-membered, nitrogen containing heterocycles that is easily opened by nucleophiles in order to relieve the strain. Yadav and co-workers demonstrated that the $\mathrm{InCl}_{3}$ could promote the ring opening of aziridines by nucleophiles including thiols under mild reaction conditions with high regioselectivity [21]. Consequently, aziridine $\mathbf{1}$ was successfully reacted with different thiols (ethylthiol, $n$-butylthiol, benzylthiol, thiophenol and $o$-methyl thiophenol) in the presence of $\mathrm{InCl}_{3}$ at room temperature to afford compounds 2a-e in high yields (63-91\%) with high stereoselectivity and regioselectivity. The next step was nucleophilic replacement of OMs group at the C-5 position by the $\mathrm{N}_{3}$ group. Treatment of compounds 2a-e with $\mathrm{NaN}_{3}$ afforded the intermediates 3a-e. The inversion of configuration at C-5 was observed for compounds 3a-e as indicated by the coupling constants of $\mathrm{H}-5$ which, had two anti $(U=8.7-9.0 \mathrm{~Hz})$ and a gauche $(J=0.0-1.0 \mathrm{~Hz})$ coupling constants. Thus, a trans relationship between $\mathrm{H}-4$ and $\mathrm{H}-5$ was revealed for compounds 3a-e. Finally, compounds 3a-e were reduced by hydrogenation in the presence of Lindlar's catalyst to provide 4a-e, respectively (Scheme 1) [19].

In the second approach, the analogues containing ether oxygen at $\mathrm{C}-3$ were also prepared starting from $\mathbf{1}$ by aziridine ring opening with alcohols in the presence of $\mathrm{BF}_{3}$. $\mathrm{Et}_{2} \mathrm{O}$ to yield compounds 5a-f which were then converted into the corresponding azide derivatives 6a-f. The series of alkyl or aryl ethers at $\mathrm{C}-3$ 7a-f was obtained from the corresponding intermediates 6a-f by reduction with $\mathrm{Ph}_{3} \mathrm{P}$ (Scheme 2) [22].

The synthetic compounds were evaluated for their cytotoxicity against three human cancer cell lines, KB (mouth epidermal carcinoma cells), LU-1 (human lung cancer cells) and MCF-7 (human breast cancer cells). Except for $\mathbf{4 d}, \mathbf{7 c}$ and $\mathbf{7 d}$, the remaining compounds were found to be active against three tested cancer cell lines (Table 1). It was found that oseltamivir has no cytotoxicity against different cell lines such as MDCK, MRC-5, VERO, MK and 293 cells [23]. Also, when tested against KB, LU-1 and MCF-7 cell lines, oseltamivir phosphate had no inhibition even at the concentration of 100 $\mu \mathrm{g} / \mathrm{mL}$. Thus, the modification of alkyl groups at C-3 of the cyclohexene ring significantly increased the cytotoxicity for this class of compounds. In order to compare the neuraminidase inhibition activity with oseltamivir phosphate, the synthetic compounds 4a-e and 7a-f were also evaluated for their in vitro influenza A neuraminidase inhibitory activity by an enzymatic assay. However, these compounds had no inhibition activity even at the concentration of $50 \mu \mathrm{M}$. This observation suggested that the 3-o-pentyl group at C-3 of oseltamivir played an important role for the neuraminidase inhibitory activity of oseltamivir. This is in agreement with the previous reports on several oseltamivir analogues such as compounds 8-11 which are less active than oseltamivir (Figure 1) [24]. 


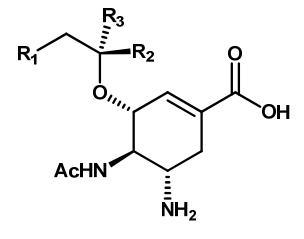

8: $\mathbf{R}_{\mathbf{1}}=\mathrm{COOH} ; \mathbf{R}_{\mathbf{2}}=\mathrm{Et} ; \mathbf{R}_{\mathbf{3}}=\mathbf{H}$

9: $R_{1}=\mathrm{COOH} ; \mathrm{R}_{2}=\mathrm{H} ; \mathrm{R}_{\mathbf{3}}=\mathrm{Et}$

10: $\mathrm{R}_{\mathbf{1}}=\mathrm{CH}_{\mathbf{2}} \mathrm{OH} ; \mathbf{R}_{\mathbf{2}}=\mathrm{Et} ; \mathrm{R}_{\mathbf{3}}=\mathrm{H}$

11: $\mathrm{R}_{1}=\mathrm{CH}_{2} \mathrm{OH} ; \mathrm{R}_{2}=\mathrm{H} ; \mathrm{R}_{\mathbf{3}}=\mathrm{Et}$

Figure 1. Compounds taken from the ref. [24].

\section{Conclusion}

We have described the synthesis and biological evaluation of oseltamivir analogues containing either ether sulfur or ether oxygen at C-3 position for cytotoxic activity. Many of the synthetic derivatives exhibited cytotoxicity against the three tumor cell lines (KB, LU-1 and MCF-7). This is the first synthesis of oseltamivir analogues with ether sulfur at C-3.

\section{Acknowledgements}

This work was supported by the Vietnam National Foundation for Science and Technology Development (NAFOSTED) and the Research Foundation Flanders (FWO) (Project No: 04/2010).

\section{References}

[1]. Rohloff, J. C.; Kent, K. M.; Postich, M. J.; Becker, M. W.; Chapman, H. H.; Kelly, D. E.; Lew, W.; Louie, M. S.; McGee, L. R.; Prisbe, E. J.; Schultze, L. M. , Yu, R. H.; Zhang, L. J. Org. Chem. 1998, 63, 4545-4550.

[2]. Federspiel, M.; Fischer, R.; Hennig, M.; Mair, H. J.; Oberhauser, T.; Rimmler, G.; Albiez, T.; Bruhin, J.; Estermann, H.; Gandert, C.; Göckel, V.; Götzö, S.; Hoffmann, U.; Huber, G.; Janatsch, G.; Lauper, S.; RöckelStäbler, O.; Trussardi, R.; Zwahlen, A. G. Org. Process Res. Dev. 1999, 3, 266-274.

[3]. Abrecht, S.; Harrington, P.; Iding, H.; Karpf, M.; Trussardi, R.; Wirz, B.; Zutter, U. Chimia 2004, 58, 621-629.

[4]. Karpf, M.; Trussardi, R. J. Org. Chem. 2001, 66, 2044-2051.

[5]. Harrington, P. J.; Brown, J. D.; Foderaro, T.; Hughes, R. C. Org. Proc. Res. Dev. 2004, 8, 86-91.

[6]. Genovese, S.; Curini, M.; Epifano, F. Phytochemistry 2009, 70, 10821091.

[7]. Floss, H. G. Nat. Prod. Rep. 1997, 14, 433-452.

[8]. Kishore, G. M.; Shah, D. M. Annu. Rev. Biochem. 1988, 57, 627-663.

[9]. Zamir, L. O.; Luthe, C. Can. J. Chem. 1984, 62, 1169-1175.

[10]. Sutherland, J. K.; Watkins, W. J.; Snow, G. A.; Davies G. M. U. S. Patent 5 $164382,1992$.

[11]. Davies, G. M.; Barrett-Bee, K. J.; Jude, D. A.; Lehan, M.; Nichols, W. W.; Pinder, P. E.; Thain, J. L.; Watkins, W. J.; Wilson, R. G. Antimicrob. Agents Ch. 1994, 38, 403-406.

[12]. Numata, A.; Iritani, M.; Yamada, T.; Minoura, K.; Matsumura, E.; Yamori, T.; Tsuruo T. Tetrahedron Lett. 1997, 38, 8215-8218.

[13]. Aghil, O.; Bibby, M. C.; Carrington, S. J.; Double, J.; Douglas, K. T.; Phillips, R. M.; Shing, T. K. Anti-cancer Drug Des. 1992, 7, 67-82.

[14]. McConkey, G. A. Antimicrob. Agents Ch. 1999, 43, 175-177.

[15]. Johansson, L.; Liden, G. J. Biotechnol. 2006, 126, 528-545.

[16]. Yamada, T.; Iritani, M.; Ohishi, H.; Tanaka, K.; Minoura, K.; Doi, M.; Numata, A. Org. Biomol. Chem. 2007, 5, 3979-3986.

[17]. Nguyen, Q. C.; Doan, T. M. H.; Le, A. T.; Pham, X. V.; Tran, T. T. T.; Pham, V. C.; Nguyen, V. H. Tap. Chi. Hoa. Hoc. 2006, 44, 745-748.

[18]. Mosmann T. J. Immunol. Methods 1983, 65, 55-63.

[19]. Nie, L. D.; Shi, X. X. Tetrahedron-Asymmetry 2009, 20, 124-129.

[20]. Liang-Deng, N.; Xiao-Xin, S.; Kwang, H. K.; Wei-Dong, L. J. Org. Chem. 2009, 74, 3970-3973.

[21]. Yadav, J. S.; Reddy, B. V. S.; Kumar, G. M.; Murthy, C. V. S. R. Synthetic Commun. 2002, 32, 1797-1802.

[22]. Lew, W.; Escarpe, P. A.; Mendel, D. B.; Sweeny, D. J.; Kim, C. U. Bioorg. Med. Chem. Lett. 1999, 9, 2811-2814.

[23]. Oseltamivir Medical Review. US FDA Center for Drug Evaluation and Research, Application No. 021087, 25 October 1999.

[24]. Kim, C. U.; Lew, W.; Williams, M. A.; Liu, H.; Zhang, L.; Swaminathan, S.; Bischofberger, N.; Chen, M. S.; Mendel, D. B.; Tai, C. Y.; Laver, W. G.; Stevens, R. C. J. Am. Chem. Soc. 1997, 119, 681-690. 